Vol. 14 (2) - Octubre 2020 - http://dx.doi.org/10.21110/19882939.2020.140211

\title{
LA INSOPORTABLE SOLEDAD DE SER UN "NO SER" Ser un "Don nadie" 1
}

\author{
Judit Deprez y Laura Molet \\ IARPP España, Barcelona
}

\begin{abstract}
Este presentación gira en torno al dolor y sufrimiento que sienten algunas personas con experiencias de graves déficits emocionales desde su primera infancia, las carencias afectivas y los vínculos de apego inseguros son el "caldo de cultivo" donde se cocinan identidades falsas, roles invertidos, identidades que se sienten invisibles o poco importantes y que no ocupan lugar ni en la mente del cuidador principal ni ocupan un lugar, es decir, lo que ellos denominan ser un "Don Nadie". Unas viñetas de dos casos clínicos sirven para ilustrar esta forma de estar en el mundo. "Que hablen bien o mal. Pero que hablen de mi", dice Antonio, el paciente de 41 años del cual iremos hablando en esta presentación. En el vínculo pacienteterapeuta es donde hay una oportunidad de iniciar una nueva manera de interactuar y de relacionarse, modificando el conocimiento relacional implícito, una segunda ocasión que tiene el paciente para acceder a un patrón de apego seguro con su terapeuta. Al ser seres relacionales, regulamos las emociones a través de las relaciones, por eso el principal foco de interés se sitúa en la relación, la interacción. "Eres el único apoyo que tengo -dice el paciente a la terapeuta-. Contigo puedo ser yo, Antonio, pero de puertas a fuera soy Anthony el traficante y adicto". Es a partir de aquí donde puede dejar de sentirse un "Don Nadie" y acceder a la singularidad de su ser, donde puede simplemente ser él mismo, gracias a que se ha sentido visto y sentido por su terapeuta. Sentirse sentido ayuda a construir la identidad.
\end{abstract}

Palabras clave: Apego, soledad, identidad, interacción, emoción.

This presentation is about the pain and suffering felt by people who, right from early childhood, have been disconnected from their emotions. Lack of affection and insecure attachment bonds are breeding grounds, "kitchens", where false identities, role reversal or identities of feeling insignificant to their caregivers are cooked; this is what they refer to as being "nobody". Two clinical cases are used to illustrate this way of being in the world. "They might say good or bad things about me, but at least they talk about me", says Antonio, the 41-year-old patient we'll be discussing in this presentation. It is within the patient-therapist bond where patients find an opportunity to learn a new way of interacting and relating to others. Modifying their implicit relational knowing, they have a second chance to build a secure attachment with their therapist. We are emotional beings, regulating emotions through our relations; thus, our principal focus is relationships/ interactions. "You're my only support," says the patient to the therapist, "I can be me, Antonio, with you; but outside I'm Anthony, the dealer and addict". It's from here on that he can forgo feeling "nobody" and gain access to his singularity: simply be himself. This can come about because he has felt listened to and seen by his therapist. Feeling felt helps to build his identity.

Key Words: Attachment, loneliness, identity, interaction, emotion. English Title: THE UNSUPPORTABLE SOLITUDE OF BEING A "NOT BEING". Being "nobody"

\section{Cita bibliográfica / Reference citation:}

Deprez, J. y Molet, L. (2020). La insoportable soledad de un "no ser". Ser un "Don nadie". Clínica e Investigación Relacional, 14 (2): 440-448. [ISSN 1988-2939] [Recuperado de www.ceir.info ] DOI: $10.21110 / 19882939.2020 .140211$

\footnotetext{
${ }^{1}$ Trabajo presentado en la VIIIa Reunión Bienal de IARPP-España, Sevilla, 18 y 19 Octubre de 2019
} 
"Me llamo Oscar y voy a empezar por presentarme a mí, y a intentar desvelar como he acabado siendo una seta".

Esta presentación gira en torno al dolor y sufrimiento que sienten algunas personas con experiencias de graves déficits emocionales desde su primera infancia, las carencias afectivas y los vínculos de apego inseguros son el "caldo de cultivo" donde se cocinan identidades falsas, roles invertidos e identidades que se sienten invisibles o poco importantes, que no ocupan lugar ni en la mente del cuidador principal ni en la sociedad, es lo que podríamos denominar ser un "Don Nadie".

La idea es plantear la posibilidad de que la consulta terapéutica pueda convertirse en una cocina (Atlas, 2017), como metáfora del inconsciente y del proceso analítico, donde siempre se está cocinando algo, aunque a veces no sepamos qué es. En la díada analista-paciente podemos aprender que aquello que se cocina está lleno de ingredientes del pasado y del presente, lo preparamos para un futuro con un nuevo patrón de relación que permita salir de los bucles repetitivos y de las dinámicas de reproches y de culpas mutuas tan habituales en los pacientes carenciales. El analista no es el chef, sino que invita al paciente a la cocina a cocinar juntos, los dos cocinan, los dos procesan, los dos modifican los platos y colaboran el uno con el otro, co-creando sesiones en las que ejercen una influencia mutua y recíproca, como en los procesos diádicos de apego del patrón mamá-bebé. Ahí es donde hay una oportunidad de iniciar una nueva manera de interactuar y de relacionarse, modificando el conocimiento relacional implícito, una segunda ocasión que tiene el paciente para acceder a un patrón de apego seguro con su terapeuta.

Es posible que un paciente considere inicialmente que la regulación interactiva es un desafío demasiado grande (Dana, 2018).

Esta afirmación nos permite introducir dos casos clínicos que nos ayudaran a describir esta "forma de estar en el mundo". En primer lugar, presentamos a Antonio, paciente de 41 años que acude a tratamiento como parte obligada de su cumplimiento de condena. En segundo lugar, a Oscar, de 35 años que empieza tratamiento de forma semi-voluntaria, derivado del departamento de justicia. Si bien es cierto que la situación de derivación es distinta en ambos casos, les une la presencia de resistencias iniciales. Se encuentran empezando tratamiento por dos motivos comunes, el principal es porqué están en la fase final del cumplimiento de una condena en un Centro Penitenciario, aspecto que lleva a los equipos de tratamiento a vincularlos a recursos para favorecer el proceso de reinserción y, el segundo motivo, para tratar un historial de adicción. Muestran comportamientos distantes e incluso agresivos en los primeros encuentros terapéuticos, seguramente sobrepasados por la idea de iniciar una 
terapia, proceso que ninguno de ellos había considerado como una posibilidad anteriormente, así como por la desconfianza que tienen tan interiorizada. Después de múltiples intentos de realizar una sesión individual con Oscar -el tratamiento combina sesiones grupales e individuales- consigo que se siente en el despacho. A pesar de estar ahí, noto su incomodidad, distancia y frialdad, y le pregunto "¿Cómo estás?" Se queda unos segundos sin poder contestar y acaba respondiendo "¿Por qué me lo preguntas? ¿Te interesa saberlo?", sin dudarlo, le digo que me interesa y que me gustaría conocerlo mejor. "Hace muchos años que nadie me preguntaba cómo estaba, me sorprende que me trates como una persona, gracias" acaba añadiendo. En ese momento percibo que él accede a entrar a la cocina conmigo. Algo común en los pacientes con historias de apego inseguro es que a menudo utilizan estrategias defensivas para minimizar las manifestaciones de apego. Por ejemplo, al inicio de la relación terapéutica esperan muy poco de nosotros dada su historia de sentirse rechazados cuando buscaban apoyo y comprensión por parte de sus figuras de apego (Cortina y Marrone, 2017).

La relación terapéutica requiere una conexión emocional estable, reguladora y vigorizante con la finalidad de establecer condiciones psicológicas y neurobiológicas necesarias para el desarrollo. Las experiencias psicoterapéuticas -al igual que la relación maternofilial- que regulan el afecto, dejan huella en las estructuras neurobiológicas responsables de la regulación de nuestros pacientes (Hill, 2018).

Sabemos que la capacidad de autorregulación debe construirse de manera óptima sobre la base de la regulación interactiva, un bebé aprende a autorregularse a partir del aprendizaje de la regulación interactiva de la díada madre-bebé en sintonía (Dana, 2018). Esta experiencia interactiva tonifica el sistema nervioso del bebé, a partir de la creación de su perfil neuronal individual. Como dice Fosha (2001), "la capacidad de experimentar plenamente los propios sentimientos, especialmente si son intensos y/o dolorosos, aumenta enormemente cuando somos capaces de hacerlo junto a otra persona que nos apoya, se pone en nuestro lugar, y está emocionalmente presente". Cuando ocurren momentos de ruptura, la madre regulada y en sintonía se da cuenta y procede a la reparación, así el bebé experimenta seguridad en la regulación interactiva y puede construir un vínculo de apego seguro (Dana, 2018).

Un historial de cuidados sin sintonía y de rupturas no reparadas configura el sistema nervioso autónomo hacia la protección y lo aleja de la conexión. Las rupturas del sistema niño-cuidador llevan a la pérdida de la capacidad de regular el afecto (Stolorow, 2004), de este modo los déficits regulatorios de la cuidadora son interiorizados por su bebé (Hill, 2018). El aislamiento y la percepción de desconexión social puede conducir a la falta de recursos interactivos. Ambas experiencias se convierten en una historia de soledad, muchas veces insoportable, que puede llevar a los pacientes a sentirse tan desesperados como para actuar de forma disfuncional o no 
poder dejar de hacerlo. "En casa se normalizaron las peleas, tanto que yo ya era impasible y consolaba a mi madre, hablaba con mi padre y calmaba a mi hermano y yo, yo me llenaba de todo ese dolor y me iba a la calle. Así comenzaron las primeras peleas. Ahí empecé a soltar mi odio, mi rabia y me sentía bien, era como mi antídoto a mis males: Vaya familia, pasan de mi, solo pelean, todo es negativo". Captamos, a través de de lo que escribe Oscar en su cuaderno terapéutico, cómo hace un registro de su experiencia para intentar descubrir por qué se siente tan desubicado, desarraigado y desamparado, solo, como una seta en medio del campo.

Después de un año y medio fuera de la cárcel viviendo diariamente con las dificultades del proceso de reinserción Oscar me comenta: "no quiero volver ahí dentro -refiriéndose a la cárcel, pero a veces pienso que estaría mejor. Ahí soy alguien, sería equivalente a tener un doctorado en tu sociedad. En prisión tengo mucho poder y mucho mando, en el patio me respetan, me dejan su sitio y si las duchas están llenas sé que alguien saldrá para dejarme entrar. En cambio, ahora me siento un pringado, estoy solo y nadie me quiere".

Antonio, que también presenta una historia de insoportable soledad, explica en una sesión que ha entrado nuevamente en una banda criminal. Me quedo sorprendida y empezamos a pensar qué ha hecho que él volviera a vincularse en un ambiente tan perjudicial, me dice "Que hablen bien o mal, pero que hablen de mi. Ese es el lema que me ha acompañado toda la vida". Me confiesa que él realmente no quiere volver a estar inmerso en el mundo de las bandas, pero que es la única forma que ha "podido" encontrar para no estar solo los fines de semana cuando sale de permiso de la cárcel o para no sentirse un don nadie, "es lo más parecido a una familia, sé que si me pasa algo ellos me van a proteger".

Los apodos que nos han caracterizado, definido y devaluado desde nuestra infancia se transforman en nuestros principios organizadores: convicciones emocionales que arrastran vergüenza y humillación acerca de quiénes somos, o la imagen que nos dan de nosotros mismos. Las convicciones invalidantes y defectuosas del sentimiento de sí mismo/a tienen una gran influencia en el desarrollo de la identidad del sujeto (Orange, 2011). "No me acuerdo de cuando era un niño, pero me han contado que era malo. Era travieso. No iba al cole, hacía campana (...) Yo era muy chiquitillo e iba con el cigarrillo en la boca, salía a la calle con otros, todos éramos de padres desestructurados. De familias normales de mi barrio. Una familia chunga, bueno chunga no, que no pueden asistirte. Mi madre, que no le echo la culpa, trabajaba y yo estaba solo todo el día (...) Estaba tres meses sin ir al colegio y nadie se enteraba hasta que los profesores llamaban a casa para hablar con mi madre". Hay otro factor de gran importancia, su padre abandonó a la familia cuando Antonio tenía 3 años, generando en él la convicción de no ser suficiente como para que su padre se quedara. Podemos pensar que ese 
mote o adjetivo de ser "malo" le condicionó la construcción de su subjetividad, ser malo es mejor que ser un don nadie.

La finalidad del sistema de apego es la disponibilidad del cuidador, que se muestre accesible y receptivo. El apego seguro implica sistemas representacionales donde la figura principal se siente como accesible y receptiva si se la necesita, uno de los objetivos principales del sistema de apego es "sentir seguridad". Las personas con apego seguro han internalizado las capacidades de autoregulación. En cambio los bebés ambivalentes han aprendido a ser hipervigilantes y a centrarse en el apego y mantener la atención a sus madres. Los bebés evasivos han aprendido a no pedir ayuda cuando están angustiados y a desviar su atención de las preocupaciones relacionadas con el apego (Hill, 2018).

En estas frases de Oscar, podemos identificar aspectos característicos del patrón evitativo: "Mi familia se dio cuenta que se tendría que armar de paciencia conmigo desde niño, así que empezaron con el pasotismo, primero poco a poco y luego total. Así que si necesitaba algo, me lo buscaba. ¿Para qué tratar con pasotas a los cuales notaba que cansaba más aun si me dirigía a ellos? Así que la calle era mi recreo. Salía de mi casa sin decir nada, el portazo era la señal de que me iba. (...) pasaba de los que pasaban de mi, para qué escuchar que me respondían con tono cansado y desinteresado". Los bebés evitativos, tienen figuras de apego que generalmente no responden o ignoran sus expresiones de desconsuelo y estrés (Cortina y Marrone, 2017).

Estos casos clínicos nos invitan a reflexionar sobre la importancia de modificar los patrones de apego inseguros para poder co-construir una forma de vinculación segura. Sabemos que las personas con un patrón relacional seguro, muestran una competencia afectiva que implica ser capaz de sentir y de procesar las emociones para un funcionamiento óptimo, manteniendo la integridad del yo, y la relación proveedora de seguridad (Fosha, 2000, p42). Dichas personas hacen un uso flexible tanto de la autoregulación como de la regulación diádica, así como su patrón de excitación del afecto es flexible y resiliente (Hill, 2018). Entendemos como resiliencia afectiva aquella capacidad que poseen algunos individuos para recuperar la homeostasis -la actividad normal- después de haber estado expuestos a una desregulación, permitiendo un funcionamiento adaptativo (Cicchetti, 2010, citado en Hill, 2018). En dicho apego seguro se produce una sintonización, un conocimiento y una aceptación de nosotros tal y como somos.

Como podemos ver, estos mecanismos no existen de la misma forma en los apegos de carácter inseguro, los niños con apegos ansiosos-ambivalentes utilizan únicamente la regulación diádica y los evasivos sólo la autoregulación. Ninguno de ellos funcionan de forma óptima, pero consiguen una estructura. Por otra parte, los niños con apego desorganizado no pueden usar satisfactoriamente ninguno de los dos mecanismos (Hill, 2018). Los déficits en una 
regulación del afecto adaptativa pueden desarrollar trastornos mentales, tales como la adicción a las sustancias.

Ambos pacientes -Antonio y Oscar- tienen un largo historial de consumo, especialmente de cocaína en ambos casos. Múltiples autores y teorías hacen énfasis en el fracaso de la internalización de la capacidad de autocuidado, teniendo como consecuencia la no regulación de la autoestima ni del afecto (González, 2008).

Los sujetos con apegos inseguros desarrollan unas emociones y expresiones habituales que son defensas que minimizan o bloquean los afectos aterradores o aversivos (Fosha, 2000). Las defensas relacionales son mucho más sofisticadas psicológicamente, al resultar de una consciencia superior que incluye el concepto de percepción del yo y una comprensión conceptual del tiempo: pasado, presente y futuro (Edelman, 1999). Cuando Oscar describe las experiencias vividas con su familia, nos damos cuenta de la construcción progresiva de estas defensas relacionales "Hoy por hoy, creo que si hubiera nacido en otra familia (...) mi vida hubiera sido totalmente distinta y hubiera conservado esa sonrisa y esos ojos alegres, que al tiempo he ido borrando. Mis ojos ahora son más tristes y mi carácter resentido, es como de derrotado o desanimado, o algunas veces de sin pena ni gloria".

A modo de síntesis, podemos concluir que los pacientes con historias de apego inseguro ansioso/ambivalente han tenido cuidadores poco fiables, cuya atención obtenían de forma intermitente, a base de ser pegajosos, señales para reclamar la atención, que llevan a un aumento de la aflicción. Se sitúan en un continuum en cuyos extremos están los histéricos, abrumados, impotentes y seductores, y los límites, enfadados, exigentes y caóticos. Presentan mayor reactividad en la edad adulta, siendo incapaces de modular la aflicción, sintiéndose muy vulnerables, a la vez que presentan un miedo elevado al abandono y se muestran preocupados por los estados emocionales internos, manifestando mucha ansiedad (Schore, 2003; Wallin, 2012).

Personas con historias de apego desorganizado han crecido con figuras que van del extremo de afectos bajos -abandono- y altos -maltrato-. Son adultos incapaces de autoregularse afectivamente o interactivamente. Pueden sentir miedos desregulados, ira, cambios drásticos, confusión de sus estado emocionales intensos, exaltación, desesperación, impotencia o un afecto plano, tienen partes de sus experiencias emocionales disociadas, lo cual evita la regulación interactiva y la auto regulación (Wallin, 2012). En el adulto, el apego desorganizado se manifiesta en problemas conductuales: control del otro, punición o inversión de roles. La relación está condicionada por agresividad y explosiones de cólera (Cortina y Marrone, 2017).

Las personas con historias de apegos inseguros evitativos desestiman las señales de aflicción interna, y minimizan sus necesidades emocionales, ya que históricamente han aprendido que 
comunicar sus emociones negativas no dio el resultado deseado y esperado, y no obtuvo cuidados para regular sus emociones. Constituyen un continuum en cuyos extremos se sitúan los narcisistas y los esquizoides. A grandes rasgos se caracterizan por tener dificultades para confiar en los demás, presentar autosuficiencia compulsiva y una sobreestimación defensiva de su propia valía. A veces estas personas no pueden comunicar sus emociones, y tampoco pueden experimentarlas, la experiencia emocional se limita (Schore, 2003). Al perder el acceso a las emociones fuertes, son pacientes que se presentan con "afecto plano". No hay experiencia afectiva, sólo "funcionamiento": son prácticos/pragmáticos.

Oscar aprendió que pedir ayuda a su familia no era útil y que se las tenía que apañar él solo. Patrón que aún persiste. Tiene fases cíclicas de 2-3 meses que empiezan con bienestar y motivación por algún objetivo propuesto, pero su baja tolerancia a la frustración y la dificultad que tiene para pedir ayuda, hacen que continúe acumulando malestar hasta el momento de explotar-consumiendo, peleándose, atracando, etc.

Estas explosiones son, por una parte la expresión gráfica del fracaso del proceso reflexivo y de autoregulación. Por otra, evidencian la importancia de tomar consciencia de que las cosas le afectan afectivamente y la necesidad de trabajar para que pueda pedir ayuda terapéutica. En estos momentos de explosión y descontrol, él siempre remarca que se siente extraño, raro y que no se entiende. Se le explica la importancia de poder "cocinar" juntos todo aquello que tiene acumulado, ya que sino su pasado seguirá interfiriendo en el presente. Al inicio del proceso terapéutico él se negaba diciendo que "el pasado pasado está, y así se tiene que quedar". A medida que las sesiones avanzaban, las resistencias iban disminuyendo, empezando a reconocer el miedo que tiene de remover todo lo vivido "¿qué pasa si no puedo tolerar todo el dolor que esto me va a suponer y acabo teniendo una gran explosión?". Le digo que ahora no estará solo en el proceso, que estamos los dos juntos y que trabajaremos para evitar estas explosiones donde siempre sale alguien herido -en las peleas son otros los que reciben el golpe, pero cuando hay consumo se daña a él mismo.

Mientras el paciente me habla de su miedo, conecto con su tristeza y sufrimiento y me lloran los ojos. Cuando me ve, puede identificar su propio dolor y tristeza a través de mis ojos, permitiéndose por primera vez unas lágrimas. "Al verte emocionada, me he emocionado yo". Después añade "Yo ya sabía que fuera las cosas no estaban bien, que mi familia no habría cambiado, que me costaría volver a estar fuera. Pero como tenía tanto tiempo por delante simplemente rechazaba estos pensamientos, pero ahora esto no lo puedo hacer, ahora estoy fuera y me estoy encontrando con la realidad y la verdad es que duele mucho". Nos hace pensar en la siguiente frase de Wallin (2012) "Los pacientes negadores suelen evocar en el terapeuta lo que son reacios a sentir. Si aportamos nuestros sentimientos a la terapia de éstos pacientes, 
podemos ayudarles a integrar sus propios sentimientos disociados". Y en la importancia de la resonancia diádica y del poder curativo de la relación terapéutica. Es desde la relación con un otro que reconoce y valida nuestros afectos y sentimientos que se pueden empezar a coconstruir patrones de relación más funcionales, a la vez que modelos operativos internos con mayor consonancia con el verdadero Self, permitiendo a los pacientes ser más capaces de aceptar e integrar las diferentes realidades en los esquemas mentales (Winicott, citado en González, 2014). Pasando de un estado de disregulación-disociación a otro de regulaciónintegración (Hill, 2018).

El silencio no te protege, es necesario darle voz dejando atrás el papel del mutismo o la ley del silencio que es insana, patológica y genera sufrimiento y sintomatología, la ley de la verdad, sin tapujos, desnuda, pero vestida de emoción, sufrimiento, dolor, afectos, es la vía hacia la libertad y hacia la salud mental para conseguir un self integrado (Molet, 2018).

A través de las interacciones emocionales nutritivas, díada madre-bebé/pareja terapéutica/pareja de amor, es probable que nos sintamos reconocidos, amados y

valiosos. Si las relaciones funcionan bien cada miembro se siente mejorado mediante la interacción con el otro. Es a partir de aquí donde pueden dejar de sentirse como un "Don Nadie" y acceder a la singularidad de su ser. Donde pueden simplemente ser ellos mismos gracias a que se han sentido vistos y sentidos por su terapeuta. Sentirse sentido ayuda a construir la identidad. "Eres el único apoyo que tengo -dice el paciente a la terapeuta-. Contigo puedo ser yo, Antonio, pero de puertas a fuera soy Anthony el traficante y adicto".

En este viaje al centro del apego hemos recorrido a través de ciertos términos teóricos y algunas viñetas clínicas, el marco conceptual y psicoanalítico intersubjetivo. Hemos usado ingredientes para cocinar algo todos/as juntos/as que permita prepararnos para un futuro próximo fortaleciendo nuestra identidad de profesión y comprendiendo a nuestros/as pacientes desde la perspectiva integradora y relacional con la que nos identificamos. Procurando dar seguridad a nuestros pacientes, que puedan captar nuestra disponibilidad emocional en sus momentos de aflicción, y puedan internalizar capacidades para autoregularse, así como aumentar su autoconciencia reflexiva. La formación de nuevos principios organizadores es lo que constituye la esencia del cambio psíquico que permite que continúe el desarrollo emocional del paciente.

\section{REFERENCIAS}

Atlas, G. (2017). El enigma del deseo. Sexo, anhelo y pertenencia en psicoanálisis. Lima: Gradiva 
Cortina, M. y Marrone, M. (2017). Apego y psicoterapia. Un paradigma revolucionario. Madrid: Psimática.

Dana, D. (2018). La teoría polivagal en terapia. Cómo unirse al ritmo de la regulación. Madrid: Eleftheria. Fonagy, P. (2004). Teoría del Apego y Psicoanálisis. Barcelona: Ed Espaxs

Fosha, D. (2001). The transforming power of affect: A model of accelerated change. New York: Basic Books.

González Guerras, J. (2014). Sobre las adicciones y... Ante la intolerancia a los afectos. ¿Trascender y/o negar la realidad? Clínica e Investigación Relacional, 8 (3): 379-393. [ISSN 1988-2939] [Recuperado de www.ceir.org.es ]

Hill, D. (2018) Teoría de la regulación del afecto. Un modelo clínico. Madrid: Eleftheria.

Marrone, M. (2001). La teoría del apego. Un enfoque actual. Madrid: Psimática

Molet, L. (2018). El dolor es sordo. Berlín: Editorial académica española.

Orange, D.M. (2011). "La actitud de los héroes": Bernard Brandchaft y la hermenéutica de la confianza. Clínica e Investigación Relacional, 5 (3): 507-515. [ISSN 1988-2939].

Stern, D. (1997). La constelación mental. Madrid: Paidós

Stolorow, R. y Atwood, G. (2004). Los contextos del ser. Barcelona: Ed Herder Wallin, D. (2012). El apego en psicoterapia. Madrid: Desclée de Brower.

Original recibido con fecha: 30/10/2019 Revisado: 30/11/2019 Aceptado: 30/09/2020 